\title{
Making Links Across the Lifespan in Neurology
}

Can. J. Neurol. Sci. 2012; 39: 1-2

Cerebral palsy (CP) still is a prevalent neurodevelopmental disability in children in Canada and worldwide ${ }^{1,2}$. However, CP is not a disability of childhood anymore. With improved neonatal and paediatric care over the last three to four decades, life expectancy has changed dramatically ${ }^{3}$. In a recent study in Sweden, Westbom et al studied survival in a population of children with CP between 1990 and $2010^{4}$. All children with the best motor abilities, and $96 \%$ of the whole population with $\mathrm{CP}$, survived into adulthood. Although the risk of death is the highest in fragile children with $\mathrm{CP}$, their estimated survival is $60 \%$ at 19 years-of-age ${ }^{4}$. The issue of growing up with CP has become a new reality. The article by Oskoui highlighting some of the challenges of adolescents in their transition into adulthood is relevant and timely for which the author is to be complemented ${ }^{1}$.

Unfortunately, there are only two studies, one in Alberta and one from British Colombia, which provide us with prevalence data of $\mathrm{CP}$ in children. Oskoui indicates the importance of developing population-based patient registries in Canada. The good news is that two recent initiatives in Canada were successful in obtaining funding: the National Population Health Study of Neurological Conditions $(2009-2013)^{5}$ and a Canadian Multi-Regional Population-Based Cerebral Palsy Registry ${ }^{6}$. Both programs aim to improve current knowledge about the prevalence, and co-morbidities of CP in Canada.

Also without recent Canadian population-based prevalence data it is clear that individuals with $\mathrm{CP}$ require ongoing services to decrease morbidity, improve quality of life, and provide costeffective care $^{7}$. As a consequence, paediatric health care providers including paediatric neurologists have to help build children and adolescents with CP for the future, while adult neurologists are, or will become, involved in the continued care of an increasing number of adults with $\mathrm{CP}$.

Over the last decade literature is emerging on the health issues, including health care utilization and developmental needs of individuals living with CP across the lifespan ${ }^{1,7}$. In a study in the province of Ontario it appears that adults with $\mathrm{CP}$ have limited health status and have complex care needs ${ }^{8,9}$. Pain, fatigue, seizures, cervical stenosis with myelopathy, as well as mental health problems such as depression and anxiety, are frequently reported neurological issues in adults with $\mathrm{CP}^{7}$. Recent reviews show a high prevalence of co-morbid conditions in adults with $\mathrm{CP}$ such as musculoskeletal problems, dental abnormalities, gastrointestinal and genitourinary problems, requiring adequate and ongoing routine medical care and dental care as a minimum ${ }^{7,10}$.

Because CP has traditionally been viewed as a disorder of childhood, adult specialists in primary care and neurology were not taught about $\mathrm{CP}$ management in their residency training ${ }^{7}$. Not surprisingly, Oskoui indicate that comprehensive care models with a lifecourse approach for adults with $\mathrm{CP}$ are few and far between ${ }^{1}$ with gaps in medical and psychosocial care for youth and adults with $\mathrm{CP}^{8}$. These gaps are most critical at transition points when young persons with $\mathrm{CP}$ and their families are facing significant changes in health care service, from paediatric care setting to adult health care. Hence the contemporary challenges of health care transition discussed in the paper by Oskoui ${ }^{1}$.

It seems that the time is ripe for change. Oskoui argues for transitional care programs to improve continuity of care and information sharing between paediatric and adult care providers and improved health outcomes ${ }^{1}$. Although it has been the paediatric health providers who have been the predominant drivers for better transitional care, adult facilities start recognizing that change in care model is needed for this population. Moreover, agencies, for example the Ontario Federation for Cerebral Palsy in Ontario, professional organizations and provincial governmental bodies are calling for change across geographical locations in Canada. While both paediatric neurologists and adult neurologists can hardly disagree with this call for action to improve transitional care, the question is how the neurology community should mobilize to change this.

The following ABCs for improvement of transitional care for youth with cerebral palsy and their families may serve as a starting point:

The A stands for "Awareness". Increased awareness of transitional issues is needed among all partners involved in the care of children and adults with $\mathrm{CP}$ and their families. For example, are paediatric neurologists aware of the long-term outcomes and health issues in adult life when they treat neonates and children with CP? Similarly, are adult neurologists aware of new opportunities to influence lifecourse trajectories of children and youth with CP? The paradigm has shifted considerably from traditional interventions aiming to 'fix' the impairments of a child with CP towards a future-oriented approach to promoting activities and participation ${ }^{11}$.

The B stands for "Be prepared". In line with recently developed best practice guidelines for transition in Ontario transition should be as a gradual process, one that should be age and developmentally appropriate, addressing the psychosocial and educational/vocational aspects of care in addition to the traditional medical areas ${ }^{12}$. Although flexible planning is advocated in the literature, the process of clinical transition should begin when the adolescent with CP is no older than 14 years-of-age ${ }^{13}$. As referred to by Oskoui, the Rotterdam Transition Profile can help to understand a young person's functioning. A functional profile, rather than the medical diagnosis alone, can be useful in designing better interventions by addressing activities youth consider important in their daily living $^{14}$.

The C stands for "Connections" and "Collaboration". Making the links is essential for overcoming the divide between 
paediatric and adult neurology. At an individual or program level one can think of creating a network of adult health care providers, build around the individual with $\mathrm{CP}$ and his or her family. Collaboration is also needed at an organizational level to provide health care providers with support and resources throughout the transition phase and throughout adulthood.

The key messages of the Oskoui paper resonate with recent developments in the field. The American Academy for Cerebral Palsy and Developmental Medicine (AACPDM, www.aacpdm .org) is an organization that was founded in 1947 to improve the care for children with CP. It has recently changed its vision and mission statement acknowledging the lifespan approach for individuals living with $\mathrm{CP}$ and their families. It also founded a "Life Span Care" committee that aims to provide leadership in lifespan care issues including transition to adulthood, aging, and adult outcomes for the benefit of people with cerebral palsy and other childhood-onset disabilities. The 66th annual AACPDM meeting will be held in Toronto, Ontario from 12 to 16 September 2012. This will be an opportunity to bring together paediatric and adult health care providers, as well as children and adults with $\mathrm{CP}$ and their families, making the links across the lifespan.

\section{REFERENCES}

1. Oskoui M. Growing up with cerebral palsy: contemporary challenges of healthcare transition. Can J Neurol Sci. 2012; 39 (1): $23-5$

2. Himmelmann $K$, Hagberg G, Uvebrant P. The changing panorama of cerebral palsy in Sweden. X. Prevalence and origin in the birth-year period 1999-2002. Acta Paediatr. 2010; 99: 1337-43.

3. Strauss DJ, Shavelle RM, Anderson TW. Life expectancy of children with cerebral palsy. Pediatr Neurol. 1998; 18: 143-9.

4. Westbom L, Bergstrand L, Wagner P, Nordmark E. Survival at 19 years of age in a total population of children and young people with cerebral palsy. Dev Med Child Neurol. 2011; 53: 808-14.

5. National population health study of neurological conditions. Ottawa: Public Health Agency of Canada; 2010 [cited 2011 Oct 18]. Available from: http://www.phac-aspc.gc.ca/cd-mc/ncmn/1-eng.php.

6. Shevell M, Miller SP, Scherer SW, Yager JY, Fehlings MG. The Cerebral Palsy Demonstration Project: a multidimensional research approach to cerebral palsy. Semin Pediatr Neurol. 2011; 1: $31-9$.

7. Aisen ML, Kerkovich D, Mast J, et al. Cerebral palsy: clinical care and neurological rehabilitation. Lancet Neurol. 2011; 9: 844-52.

8. Young NL, McCormick AM, Gilbert T, et al. Reasons for hospital admissions among youth and young adults with cerebral palsy. Arch Phys Med Rehabil. 2011; 1: 46-50.

9. Young NL, Rochon TG, McCormick A, Law M, Wedge JH, Fehlings D. The health and quality of life outcomes among youth and young adults with cerebral palsy. Arch Phys Med Rehabil. 2010; 1: 143-8.

10. Gorter JW. Rehabilitative therapies for the child with cerebral palsy: focus on family, function and fitness. Minerva Pediatr. 2009; 4: 425-40.

11. Rosenbaum P, Gorter JW. The 'F-words' in childhood disability: I swear this is how we should think! Child Care Health Development. 2011 Nov 1. doi: 10.1111/j.1365-2214.2011.013 38.x. [Epub ahead of print].

12. Stewart D, Freeman M, Law M, et al. "The best journey to adult life" for youth with disabilities: an evidence-based model and best practice guidelines for the transition to adulthood for youth with disabilities. Hamilton, ON: McMaster University and CanChild Centre for Childhood Disability Research; 2009 [cited 2011 Oct 18]. Available from: www.canchild.ca.

13. Gorter JW. Transition to adult-oriented health care: perspectives of youth and adults with complex physical disabilities. Phys Occup Ther Pediatr. 2009; 4: 362-6.

14. Gorter JW, Stewart D, Woodbury-Smith M. Youth in transition: care, health and development. Child Care Health Dev. 2011 Nov;37(6):757-63. 